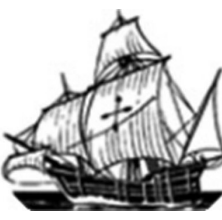

Nau Literária: crítica e teoria de literaturas • seer.ufrgs.br/NauLiteraria

ISSN 1981-4526・PPG-LET-UFRGS • Porto Alegre • vol. 09, n. 01 • jan/jun 2013

Dossiê: Voz e Interculturalidade

\title{
Panorama das representações da cultura oral e da figura indígena na literatura brasileira
}

\author{
Márcio Passos de Azambuja ${ }^{1}$
}

\begin{abstract}
Resumo: A visada deste trabalho objetiva traçar um panorama das formas de representação do indígena e da sua cultura oral na literatura brasileira através das diferentes épocas, estilos literários e correntes de pensamento que permearam as obras mais representativas da nossa literatura. Desde a época do descobrimento e da literatura informativa até a recente produção indígena de uma literatura própria, houve diversas perspectivas e objetivos por trás dessas representações do índio e sua tradição oral. Essa evolução forma um padrão da nossa forma de perceber, de nos relacionarmos e de como somos percebidos pelos habitantes originais da nossa terra. Tomandose como inegável a contribuição da cultura dos povos indígenas ao projeto de nação que denominamos Brasil, investigaremos qual a valoração que tal identidade possuiu no decorrer dos tempos utilizando textos de Lúcia Sá (2007) e Sergio Medeiros (2002) e conceitos como nação moderna, margens, narrativa e minoria de Bhabba (1994) e cosmopolitismo de Appiah (2008) construiremos um modelo de como é absorvida a tradição oral do indígena brasileiro e a sua figura na literatura e no processo de criação da identidade brasileira durante o decorrer da formação do Brasil como nação. Sempre sendo apresentada ou tutorada por um antropólogo, indigenista, cientista social ou por um escritor ou poeta de descendência europeia, a cultura oral indígena e os seus representantes legítimos sempre refletiram os anseios e temores, as filosofias e políticas da civilização dominante que cresce e evolui à margem de sua própria. De tempos em tempos a sociedade se vê envolvida em alguma forma de celebração ou resgate ao índio e, ou aos seus valores e tradições, mas nem sequer é contemplada qualquer oportunidade de um mergulho mais profundo na cultura e civilização indígena, no homem índio e nas relações que foram estabelecidas entre índios e não-índios com o passar dos tempos. Analisaremos a literarização dos fatos, descobertas, especulações e mitos sobre a fugaz cultura oral indígena e o índio, este ilustre desconhecido.
\end{abstract}

Palavras-Chave: Oral; Literatura; Brasileira; Índio; Cultura.

Abstract: The target of this work aims to outline a comprehensive overview on the ways to represent the indigene and his oral culture in Brazilian literature through different periods, literary styles and currents of thought which permeated the most representative works of our literature. Since the time of discovery and informative literature until the recent indigenous production of their own literature, there were lots of perspectives and goals beyond these representations of the Indian and his oral tradition. This evolution forms a pattern of our way to perceive, relate, and the way that we are perceived by the original inhabitants of our land. Taking as undeniable the contribution of the indigenous people culture to the project we call Brazil, we will investigate the value that such identity possesses in the course of time using texts by Lúcia Sá (2007) and Sergio Medeiros (2002) and concepts such as modern nation, margins, narrative and minority by Bhabba (1994) e cosmopolitanism by Appiah (2008) we will build a model of how the oral tradition of the Brazilian indigene is absorbed and his figure in literature and in the process of creation of the Brazilian identity during the course of the formation of Brazil as a nation. Always being introduced or tutored by a anthropologist, indigene scholar, social scientist or by a writer or a poet from European descent, the indigene oral culture and its true representatives always reflected the wishes and fears, philosophies and politics of the dominant civilization whom grows and develops itself besides their own civilization. From times to times society is caught involved in some sort of celebration, revival or rescue of the Indian and, or, his values and traditions, but it is not at least gazed any opportunity of a deeper dive in the indigene culture and civilization, in the Indian man and in the relationships established between Indians and non-Indians in the course of times. We shall analyze the literalization of the facts, discoveries, speculations and myths about the swift indigenous oral culture and the Indian, this illustrious unknown.

\footnotetext{
${ }^{1}$ Mestrando do curso de Pós-Graduação em Letras da UFRGS.
} 
Keywords: Oral; Literature; Brazilian; Indian; Culture.

Mais do que o achamento de um novo mundo, as grandes navegações transformaram a Europa e o resto do globo através do encontro com um novo homem. Os homens nativos americanos fizeram surgir uma nova concepção do gênero humano que afetaria a economia, a cultura, a política e a religião de maneiras muito profundas e duradouras através dos tempos que viriam. A real extensão e profundidade de sua influência sempre permaneceriam desafiadoras e desconhecidas para o homem europeu.

Começou com um mal-entendido. Quando os primeiros europeus entraram em contato com o homem americano este recebeu a errônea denominação de "índio"; uma explícita alusão à Índia, país asiático fabuloso e repleto de riquezas que já povoava o imaginário dos europeus, portugueses e espanhóis principalmente. O continente e o indígena americano apenas deram vida a esse espaço e ser inventados, seja a Índia ou o Éden, seja os indianos ou os homens primitivos, tudo englobado em um único e multifacetado imaginário repleto das projeções e recalques do homem da Europa.

Desde então uma série de interpretações e conceitos tentam explicar as origens e motivos das mudanças desencadeadas a partir de 1492. Uma diversidade até então inimaginável que inclui canibais nus vivendo em formações tribais nômades ou vastos impérios territoriais que se dedicavam à construção de pirâmides e sacrifícios humanos, todos dotados de complexas cosmogonias, calendários e efetivas medicinas tradicionais. Os oriundos da Europa cristã acabariam sendo obrigados a reconhecer a humanidade de seres infinitamente diferentes deles.

O grande impacto dos descobrimentos se deu mesmo no plano mental: entrar em contato com novas formas de organização social, estruturas políticas, hábitos alimentares, religiosidades; enfim novas culturas, trouxe aos europeus a noção de que os homens eram em sua natureza, muito moldáveis e que não havia apenas a sua forma de se relacionar com o mundo e com os outros seres humanos e mesmo com as divindades. Teólogos, filósofos e escritores produziram intensamente, por meio de debates falados e escritos, reflexões sobre o que seria a essência da humanidade, abrindo portas para o que mais tarde, no século XVIII, seria formulada como "natureza humana", rejeitando - ou pelo menos, se abrindo à possibilidade para tal - a superioridade dos cristãos europeus sobre a totalidade dos grupos dispersos no globo. 
Diversos viajantes europeus que aqui estiveram no século XVI registraram no papel suas observações sobre a terra e seus habitantes. Fizeram-no por obrigação profissional ou motivos pessoais. Seus textos são basicamente depoimentos e relatos de viagem, com a finalidade de apresentar aos compatriotas um panorama do novo mundo e um retrato do novo homem. Sob forma de carta, diários, tratados ou crônicas esses textos informativos foram escritos principalmente por portugueses.

O primeiro texto é a Carta a El-Rei Dom Manuel sobre o descobrimento do Brasil, escrita por Pero Vaz de Caminha entre abril e maio de 1500, quando a frota de Cabral se preparava para deixar o Brasil, seguindo em direção à Índia. Nela, o escrivão da armada dá conta do descobrimento da terra, descrevendo seus aspectos físicos e os contatos com os nativos. Foi a carta de achamento que fez o escrivão passar à história. Escrita entre os dias 26 de abril e $1^{\circ}$ de maio de 1500 , tem como objetivo informar ao rei de Portugal, D. Manuel I, o descobrimento e apresentar-lhe o que aí se encontrou. A carta revela um estilo claro, marcado pela objetividade que convém a um relatório. Os fatos aparecem narrados em ordem cronológica, desde o começo da viagem, em 9 de março, até o momento de deixar o Brasil, em 2 de maio.

Mas o texto acaba sendo mais do que apenas um inventário de fatos, pois o escrivão não se comporta como um simples burocrata. A carta é a primeira expressão do deslumbramento e ao mesmo tempo dos equívocos e intenções do colonizador português através de uma linguagem fluente e poética, com certo senso de humor, embora um tanto grave, de mistura com um ou outro trocadilho malicioso. É o ponto de partida da exaltação e valorização da terra aos olhos do colonizador, a quem são apontados suas vantagens e possíveis riquezas, ao mesmo tempo em que pretende colocar em primeiro plano o ideal português de propagação da cristandade, o que encontraria um campo aberto no elemento indígena.

Outra narrativa é o relato do piloto anônimo sobre a viagem de Pedro Álvares Cabral. Até hoje há divergências sobre o autor e o texto da narrativa. O estilo da narração assemelhase ao de outras produzidas desde o século XV e deve ter sido obra de um português que tivesse uma educação humanista e conhecesse a literatura da época. Faz um relato não só da estada da frota no Brasil como também de toda a viagem. As referências nos relatos são de encanto e incomunicabilidade com os nativos. 
Da autoria dos portugueses segue-se à carta de Caminha e a do piloto anônimo uma série de outras obras. Entre elas pode-se destacar o Diário da Navegação da Armada que foi à Terra do Brasil de Pero Lopes de Souza, que narra minunciosamente a expedição de Martim Afonso, em 1532, ou o Tratado Descritivo do Brasil em 1587, do senhor de engenho Gabriel Soares de Souza, que procura traçar um amplo panorama da colônia, em seus aspectos humanos, históricos, geográficos e econômicos.

Entretanto, europeus de outra nacionalidade que aqui estiveram, também deixaram documentos importantes sobre o Brasil de então. É o caso de Duas Viagens ao Brasil (1557), do alemão Hans Staden, que descreve pormenorizadamente o modo de vida dos tupinambás, dos quais foi prisioneiro em 1554. Duas Viagens ao Brasil está dividido em duas partes. A primeira narra a chegada do viajante ao país e sua captura pelos índios. Organizada com muita objetividade, a narrativa envolve o leitor com a sucessão de peripécias que compõem o relacionamento entre Staden e os tupinambás. A segunda descreve com precisão etnográfica, os nativos e seu modo de vida, tornando o autor, uma das principais fontes históricas e antropológicas acerca dos indígenas. Na segunda parte, revela-se o etnógrafo quinhentista, abordando alguns dos costumes tupinambás: a poligamia, o casamento e a antropofagia.

Também se destacam Viagem à Terra do Brasil de Jean de Léry que juntamente com Staden e seu conterrâneo Thevet se estabelece como fundamental para o entendimento do homem daquela época, tanto o homem europeu quanto o homem americano, guardando-se, é claro, as devidas proporções tendo em conta a visão predominantemente eurocêntrica que era apresentada nas obras. Os desentendimentos entre calvinistas e papistas na ilha de Coligny, sede da colônia, levaram-no ao continente onde conviveu com os índios, observando atentamente seu modo de vida. A narrativa apresenta os momentos iniciais da França Antártica, detendo-se em seguida nas descrições da terra e do modo de vida dos seus nativos. É justamente a parte relativa aos indígenas que destaca o texto do autor, transformando-o em um referencial dos estudos antropológicos brasileiros. Léry revela em toda a sua obra uma qualidade notável, raríssima em seu tempo de paixões e preconceitos e só encontrável atualmente nos espíritos mais adiantados de nossa civilização ocidental: senso de relatividade dos costumes, a "simpatia" no sentido sociológico da palavra, que conduz à compreensão dos semelhantes e a análise objetiva de suas atitudes. 
Igualmente documentando a tentativa de colonização francesa comandada por Villegaignon, As singularidades da França Antártica de André Thevet cuja primeira edição data de 1557 relatam suas aventuras, bem como descreve a terra que conheceu. Além das informações sobre a terra, o autor levou também para a França o tabaco, sendo considerado o introdutor desta planta em seu país. Os estudiosos supõem que Thevet tenha origem familiar pobre e tenha estudado tardiamente, obtendo uma formação deficiente, o fato se reflete em sua obra, em que se encontram frequentemente erros e concepções errôneas. Além disso, são comuns as citações de autores clássicos, como tentativa de demonstrar uma erudição que efetivamente não possuía. Por outro lado Thevet escreve bem; seu estilo é marcado pela simplicidade e pela objetividade, que se impõem mesmo nas passagens de maior pedantismo. As Singularidades da França Antártica apresenta linearmente a viagem do autor; desde a partida até o retorno ao mesmo país no ano seguinte. De seus oitenta e três capítulos, a grande maioria refere-se ao Brasil, com observações geográficas, botânicas e antropológicas. Expurgada de seus Aristóteles e de seus Plínios, posto de lado o moralista ingênuo e simplório, a obra de Thevet é útil e interessante, os estudos sobre a antropofagia dos tupinambás estariam incompletos sem a sua obra. E, do mesmo modo, o estudo dos pajés, das ornações bélicas, das práticas mortuárias, das doenças e o de certos aspectos da civilização material dos indígenas do Brasil. Além disso, pela riqueza e precisão de detalhes a obra de Thevet, Staden e Léry contribuem muito, tratando-se de textos fundamentais para o conhecimento dos índios, os primeiros habitantes do país.

Missionários jesuítas também estiveram no Brasil, a partir do Primeiro Governo Geral. Seu objetivo principal era catequizar os índios, convertendo-os ao cristianismo. Mas seu trabalho acabou ultrapassando os limites religiosos e interferiu em diversos aspectos da vida colonial, particularmente com a criação de escolas e vilas. Os jesuítas também nos legaram obras sobre o período como as cartas, de Manuel da Nóbrega e José de Anchieta, fundadores da cidade de São Paulo.

Apesar de pouco tempo de Brasil, a primeira carta de Nóbrega é um relato detalhado da vida cotidiana da capital da América Portuguesa. A primeira observação, como um bom jesuíta dos primeiros tempos, é sobre a moral dos habitantes da Bahia. Logo os jesuítas iniciaram o trabalho de evangelização dos índios começaram com as crianças, aprendendolhes a língua. Aos adultos, pregavam contra a poligamia e a antropofagia. A preocupação com a nudez dos indígenas levou Nóbrega a já ensaiar os primeiros passos da especificidade do 
cristianismo brasileiro. Para Nóbrega o problema não era a nudez dos indígenas, mas os maus exemplos que os cristãos que não confessavam e viviam em pecado lhes davam. Como provincial dos jesuítas do Brasil, Nóbrega fez diversas solicitações ao governador-geral Duarte da Costa para que proibisse os índios de comer carne humana e os reunisse em aldeias sob o controle da coroa. A sua obra é um documento notável pelo equilíbrio com que o sensato jesuíta apresentava os aspectos "negativos" e "positivos" do índio, do ponto de vista de sua abertura à conversão.

José de Anchieta, em colaboração com Manuel da Nóbrega, fundou um colégio para os indígenas que se tornou o núcleo da cidade de São Paulo. Paralelamente ao trabalho religioso, Anchieta desenvolveu constante atividade literária, escrevendo numerosos autos teatrais com finalidade catequética, entre os quais se podem citar Dia de Assunção, Vila de Vitória, Festa de Natal e Festa de São Lourenço. Em vida, publicou somente um estudo linguístico, Arte da Gramática da Língua Mais Usada na Costa do Brasil (1595), os seus autos são definitivamente pastorais no sentido eclesial da palavra, destinados à edificação do índio e do branco em certas cerimônias litúrgicas e suas cartas cujo teor semelhante ao dos outros prosadores do período inserem-se na tradição informativa da literatura do Brasil quinhentista.

Esse conjunto de textos - produzidos no Brasil ou apresentando a colônia como tema constitui a fonte original que nos permitiu o conhecimento dos fatos históricos. Em sua totalidade, as obras documentam os vários aspectos da implantação do processo colonial em território brasileiro. Nesse sentido sua importância histórica é indiscutível: trata-se do relato dos acontecimentos pela perspectiva privilegiada de participantes ou testemunhas oculares. Toda historiografia sobre o período é tributária dessa literatura de informação. Mas não se esgota aí a riqueza desses textos, em que também se podem encontrar valores estéticos, que os aproximam de textos literários.

Dada sua finalidade principalmente informativa, a linguagem dos textos do século XVI em geral não admite metáforas nem outros artifícios estéticos. Entretanto, o caráter narrativo da maioria das obras e a capacidade imaginativa dos autores contribuem para fazêlos superar o caráter utilitário dos relatórios burocráticos ou científicos. Nas obras, a anedota, a aventura e a fantasia se misturam com as informações sobre a terra e os acontecimentos históricos, gerando narrativas com as quais o leitor e o autor não conseguem deixar de se 
envolver e que se distanciam cada vez mais da objetividade de uma análise ou descrição de caráter científico rumo à subjetividade do europeu frente a um novo mundo e um novo homem.

Assim as qualidades estilísticas se unem à criatividade e às manifestações de emoção dos autores, modificando o caráter informativo e utilitário dos textos do século XVI e neles revelando valores artísticos e literários. Esses valores são reforçados na medida em que os textos apresentam particularmente o deslumbramento e o entusiasmo, a repulsa e as intenções do europeu diante da natureza exuberante e do homem dos trópicos.

Essas sensações são a base de um sentimento de afeto pelo território que veio a se desenvolver em seus novos habitantes. Manifestou-se gradualmente ao longo do século XVI, até se transformar num modo de pensar, o Nativismo, que valorizava a Colônia e mesmo seus habitantes originais, chegando a considerá-los como o futuro do Reino de Portugal. O Nativismo representou o estabelecimento dos conflitos de visão de mundo que permitiram diferenciar a mentalidade dos habitantes e nativos do Brasil, do pensamento dos reinóis, isto é, dos naturais do reino lusitano. Nesse sentido, foi um dos primeiros passos do povo brasileiro em direção à independência e à construção da nacionalidade.

Apresentando-se de forma embrionária nos textos do século XVI, o Nativismo tornouse uma característica essencial das obras do Barroco e do Arcadismo, nossas primeiras escolas literárias, que se manifestaram respectivamente nos séculos XVII e XVIII. Vistos por essa ótica, a compreensão do desenvolvimento histórico da literatura brasileira no período colonial tem como pré-requisito o conhecimento dos textos informativos produzidos entre 1500 e 1600 .

Mas não se esgota aí a sua importância para os estudos coloniais e de literatura brasileira. Seus textos também repercutiram em muitos autores brasileiros dos séculos posteriores. Em meados do século XIX, num momento histórico marcado pela necessidade de afirmar a nacionalidade adquirida recentemente, os escritores do Romantismo, como Gonçalves Dias e José de Alencar, vão pesquisar as origens do país nos textos quinhentistas. Deles extraem a imagem do índio impregnada da visão colonial que utilizarão como personagem-símbolo da nacionalidade. 
Todo um histórico de violências e abusos entre o colonizador português e o índio é resolvido através do simples apagamento de qualquer referência à brutalidade dessa relação. A exploração e a degradação a que os nativos foram submetidos em níveis que foram além do concebível pelo urbano leitor do Rio de Janeiro do século XIX não são sequer trazidos à tona e ao invés disso, ironicamente, são ofuscadas e substituídas pela relação romântica de origem medieval então revestida com uma nova roupagem inter-racial que supostamente nutriria a formação da nação brasileira. Ou seja, temos a figura do índio gozando de um certo destaque, mas desta vez totalmente desprovida de sua essência indígena. Apenas uma casca nacional recheada de valores morais e éticos da cristandade e das características do herói medieval importados de além-mar. A cultura indígena só aparece em breves vislumbres que se prestam muito mais para contextualizar esse simulacro de índio e justificar uma origem nativa da nossa civilização. São elementos acessórios à caracterização de um tipo humano congelado no tempo passado e aprisionado no espaço da selva apresentados superficialmente e sem qualquer compromisso com a veracidade da cultura indígena real.

Outra abordagem apresentada na época foi a de uma assimilação de referências clássica em que o europeu faz o papel de Prometeu renascentista que chega para presentear o fogo da colonização ao homem americano. Tal feito seria admirado e desejado profundamente pelo nativo por considerar o colonizador como portador de qualidades de procedência divina e modelo de superioridade humana imbuído de uma missão, um propósito evolutivo que objetivava o bem maior da humanidade.

É o eurocentrismo travestido de nativismo e nacionalismo. Já nessa época se consolida o hábito de olhar para um índio do passado que já não mais existe, legando ao indígena do presente, aquele que porventura tenha sobrevivido ao colonialismo, à sina da invisibilidade social, política e histórica. A literatura transformou o indígena em uma lenda de um passado remoto selvagem, como um dinossauro extinto, subtraindo sua figura do convívio com os brasileiros do tempo presente em que ocorria a construção do projeto de nação brasileira e do espaço urbano e rural onde se desenvolviam nossas relações políticas, econômicas e culturais nacionais. Talvez devido às diferenças encontradas na América Espanhola e Portuguesa tenhamos produzido nossa visão do indígena americano. A Coroa Espanhola encontrou cidades fabulosas com seus habitantes vivendo em sociedades extremamente organizadas e que em alguns aspectos superavam as mais avançadas civilizações europeias como a astronomia e o saneamento básico só para citar alguns itens. Os nativos possuíam o domínio 
de diversas artes e também considerável riqueza oriunda da exploração de outras comunidades próximas e dos recursos naturais americanos como ouro, prata e pedras preciosas além das plantas e animais. Já a Coroa Portuguesa encontrou os habitantes vivendo em sociedades de organização muito diversa. Habitando selvas ou ambientes inóspitos para o europeu, vivendo em estruturas rudimentares e dedicando-se a atividades de subsistência, o indígena brasileiro foi percebido como menor na hierarquia dos povos nativos americanos. Talvez como um estágio de evolução anterior ao dos povos que deram origem aos impérios Maia, Inca e Asteca. O homem nativo da América Portuguesa foi descrito como um primitivo de mentalidade e concepções infantis aleijado de autonomia e incapaz de ser o protagonista de sua própria história. A percepção do colonizador era de um homem despossuído; sem roupas, sem Deus, sem riquezas materiais e sem uma civilização decente e que possuísse uma cultura digna de valor e observação para um olhar apenas sensível às bizarrices e idiossincrasias concernentes a cada etnia. Devido a isso o Brasil e seus habitantes originais permaneceram anos sem receber atenção direta da Coroa Portuguesa. Sendo percebidos apenas como uma generosa fonte de recursos naturais, incluindo-se aí o índio que era concebido como uma parte humanoide da natureza e dos recursos nativos que o colonizador poderia dispor como e quando bem entendesse em seu enorme latifúndio português para satisfazer os desígnios do Rei ou de Deus. Um soldado para os generais, um escravo para os senhores, um fiel para os bispos, um guia para os exploradores, um inimigo para os conquistadores... nunca alguém com um valor que bastasse por si mesmo nada além de um mero prestador de serviços

Por outra perspectiva, a primeira geração do Modernismo vai se debruçar sobre os textos do século XVI para propor uma nova noção de nacionalismo, que questionava satiricamente os padrões culturais europeus seguidos no Brasil. A Carta de Pero Vaz de Caminha é ironizada no capítulo IX (Carta pras Icamiabas) do Macunaíma, de Mário de Andrade. No livro Pau-Brasil, Oswald de Andrade compôs vários poemas com frases extraídas dos autores do século XVI, de modo a criar uma versão paródica do modo tradicional de narrar a história do Brasil. Novamente o foco está no passado, em um índio que já não é mais. Ao invés de mergulhar no presente do índio, na sua realidade cotidiana atual, os escritores debruçam-se nas beiradas recolhendo o que mais for de serventia para destaque de seus próprios projetos de arte e nacionalismo. Era um nacionalismo sem a xenofobia onde artistas estudados nas tradições europeias se revestiam de um verniz de primitivismo, por conseguinte temos assim uma arte indígena produzida pela elite branca urbana que até 
esboçou algumas investidas na direção do nativo original brasileiro, mas são interações tímidas que resultaram em obras que não deram nenhum destaque aos artistas indígenas e nem privilegiaram a sua situação no momento. O diálogo se deu entre os civilizados eruditos e índios marginalizados que estavam muito distantes da realidade de um movimento cultural modernista urbano que demonstrava pretensões de ressignificar a nossa civilização sob os aspectos sociais, estéticos, políticos, morais e éticos.

Na década de 90 do século XX ocorre a publicação da autobiografia de Kaká Werá Jecupé intitulada Todas as Vezes que Dizemos Adeus assinala o nascimento de uma literatura indígena brasileira com a inserção da realidade contemporânea do índio brasileiro repleta de suas questões, conflitos, belezas e tragédias. $\mathrm{O}$ autor demonstra um profundo conhecimento da cultura brasileira europeizada através de inúmeras referências literárias, culturais e políticas em um processo de parodização e ressignificação da atual condição identitária, política, econômica e social do indígena brasileiro.

O cenário que situa os indígenas na imensa cidade de São Paulo, lugar improvável para habitat de uma tribo. E a grande mudança de paradigma se dá quando o fluxo que provém da cultura indígena em direção à cultura brasileira com o objetivo de criação identitária nacional que sempre ocorreu na nossa literatura é invertido revelando o processo de abrasileiramento cultural do índio e sua cultura que ocasiona a fragmentação e o desaparecimento da identidade da população indígena e das suas reais possibilidades de expressão.

Esta obra inaugura o pontapé inicial de uma literatura brasileira de caráter indígena escrita por índios. Podemos observá-los tomando a própria cultura em suas mãos e tornandose protagonistas de sua própria história e construções de identidade e de sentido no mundo atual. Uma vez que os livros que contam a história indígena sempre foram produzidos pelo homem branco, colonizador do além-mar ou conterrâneo, pouco interessado ou comprometido com o ponto de vista e a identidade indígena, adentramos um campo totalmente novo que é a literatura que se dispõe a contar a história do indígena pelo seu ponto de vista e escrita por ele mesmo, agora responsável pela criação e consolidação de sua identidade, de seu ponto de vista e dos seus meios de expressão e valor na nossa literatura.

$\mathrm{O}$ que vem a seguir ainda permanece incerto, mas apenas por podermos testemunhar essa inversão e a retomada de elementos tão caros à nossa identidade e a revaloração por si 
mesmo do universo nativo americano sabemos que além do benefício para a população indígena tão aviltada, todos comprometidos com a evolução responsável do nosso projeto de nação ganham com a ascensão de escritores, e artistas em geral oriundos da tradição indígena brasileira que tornam cada vez mais o Brasil em um país de índios também. A contribuição criada para as crianças indígenas e não indígenas que poderão se deparar futuramente com uma nova história e uma nova literatura brasileira quando chegarem à idade de seus questionamentos é enfim inestimável e incrivelmente poderosa e poderá influenciar uma geração diversa de homens e mulheres brasileiros índios e não-índios muito mais conscientes de sua identidade e propósito no mundo. Atualmente em uma sociedade de ipads, ipods e de uma cultura digital que já declarava o livro um protagonista ultrapassado vivenciando seus estertores derradeiros, podemos observar os escritores e artistas indígenas reinventando o objeto livro em seus aspectos referentes à linguagem, estética, temática e função, e decorrente disso uma revolução dentro da própria literatura brasileira. Processo que os "civilizados" desconhecem até onde pode nos levar como nação e como cultura, mas que está profundamente explícito no intento desses homens nativos americanos que contribuíram com tanto para o Brasil e parecem contribuir cada vez mais sem o mínimo sinal de esgotamento e agora realizando transformações balizadas por nada além da sua própria vontade, valores e necessidades, enfim protagonistas de seu próprio e majestoso espetáculo.

\section{Referências}

ALENCAR, José de. Iracema. (1ª ed. 1857) Rio de Janeiro: Editora Record, 1998.

ALENCAR, José de. O Guarani. (1ª ed. 1865) 8ª ed. São Paulo: Editora Ática, 1979.

ANCHIETA, José de. Santa In ês, Carta e Arte de gramática da língua mais usada na. costa do Brasil. 1563 e 1595. E-book d a Biblioteca Digital Curt Nimuendajú de livros e artigos sobre línguas sul-americanas disponível e m

http://biblio.etnolinguistica.org/autor:jose-de-anchiet, acessado em 07 Out 2013.

ANCHIETA, José de. Cartas, informações, fragmentos históricos e sermões 1554-1594. Rio de Janeiro: Civilização Brasileira, 1933.

ANCHIETA, José de. Cartas: correspondência ativa e passiva. SP: Loyola, 1984. 
ANDRADE, Mário de. Macunaíma, o herói sem nenhum caráter. ( $1^{\mathrm{a}}$ ed. 1928). $15^{\mathrm{a}}$ ed. São Paulo: Livraria Editora Martins, 1978.

ANDRADE, Oswald. Pau Brasil. (1ª ed. 1925). 2a ed. São Paulo: Globo, 2003.

CAMINHA, Pero Vaz. Carta a El Rei D. Manuel, (1ª ed. 1500) Editora Dominus: São Paulo, 1963.

CARDIM, Fernão. Tratados da Terra e Gente do Brasil. (1ª ed. 1580) BH: Itatiaia; SP: EDUSP, 1980.

CORTESÃO, Jaime. Relação do Piloto Anônimo ( $1^{\mathrm{a}}$ ed. 1530) in Jaime Cortesão $-A$ Expedição de Pedro Alvares Cabral e o Descobrimento do Brasil, Portugália, Lisboa, 1967.

GANDAVO, Pero de Magalhães. Tratado da Terra do Brasil. 5. ed. ; História da Província Santa Cruz a que vulgarmente chamamos Brasil, 1576. 12. ed. 5. ed. Recife: Massangana, 1995.

LÉRY, Jean de. Viagem à terra do Brasil. (1 ${ }^{\mathrm{a}}$ ed. 1578) Belo Horizonte: Itatiaia; São Paulo: EDUSP, 1980.

MEDEIROS, Sérgio (org.). Makunaíma e Jurupari: Cosmogonias Ameríndias, São Paulo, Editora Perspectiva 2002.

NÓBREGA, Manuel da. Cartas Jesuíticas I. BH: Itatiaia; SP: EDUSP, 1988.

NÓBREGA, Manuel da. Cartas do Brasil Mais Escritos (Opera Omnia), ed. Serafim Leite, I. Universidade, Coimbra, 1955.

SÁ, Lúcia. Anti-colonialismo na Pós-colônia: Kaká Werá Jecupé ou a literatura indígena da megalópolis. Sanches, Manuela Ribeiro (org.) Portugal Não é Um País Pequeno. 2006.

Olivieri, Antonio Carlos. Villa, Marco Antonio. (org.) Cronistas do Descobrimento, Fundação Nestlé de Cultura. São Paulo, Editora Ática, 1999.

SOUZA, Pêro Lopes de. Diário da navegação da armada que foi á terra do Brasil em 1530 sob a Capitania-Mor de Martin Affonso de Souza. (1 $1^{\text {a }}$ ed. 1532) Lisboa: Typ. da Sociedade propagadora dos conhecimentos uteis, $\underline{1839}$. Exemplar da Universidade de Harvard digitalizada por Google Books: Diário da Navegacao de Pedro Lopes de Souza. Disponível em http://books.google.com.br/books/about/Diario_da navega $\% \mathrm{C} 3 \% \mathrm{~A} 7 \% \mathrm{C} 3 \% \mathrm{~A} 30$ da armada que foi.html?hl=pt-BR\&id=F8CAAAAYAAJ\&redir esc=y acessado07 Out 2013.

SOUSA, Gabriel Soares de. Tratado descritivo do Brasil em 1587. ( $1^{\mathrm{a}}$ ed. 1587) $9^{\mathrm{a}}$ ed. Recife: Fundação Joaquim Nabuco, Ed. Massangana, 2000.

STADEN, Hans. Duas viagens ao Brasil. (1 $1^{\text {a }}$ ed. 1557) Belo Horizonte: Ed. Itatiaia; São Paulo: Ed. da Universidade de São Paulo, 1974. 
THEVET, André. As singularidades da França Antártica. (1 $1^{\mathrm{a}}$ ed. 1557) Tradução de Eugênio Amado. Belo Horizonte: Ed. Itatiaia. São Paulo: Ed. Da Universidade de São Paulo, 1978. 